\title{
A aspirina, os opiáceos e a maconha no sistema endógeno de controle da dor
}

\author{
Horacio VANEGAS
}

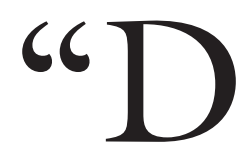

OR é aquilo que sentimos quando algo nos machuca." Essa é minha definição "de bolso" para uma experiência subjetiva extremamente complexa causada pelo dano em algum de nossos tecidos. A dor tem um componente psicofísico que permite avaliar a localização do dano, sua extensão, sua intensidade etc., assim como seu caráter queimante, eletrizante, opressivo, pulsátil etc. A dor tem, além disso, um componente emocional negativo ou aversivo: é uma sensação desagradável que toda pessoa normal deseja que acabe logo. Em todo o planeta, a dor é a razão principal pela qual as pessoas procuram o médico.

Vale enfatizar que, do ponto de vista epistemológico, a dor é um fenômeno em primeira pessoa. Se uma pessoa A sofre um dano, a experiência psicofísica e emocional gerada por ela só é vivenciada pela pessoa A. Uma pessoa B, ainda que A conte detalhadamente o que sente, embora imagine o que sinta A e até sofra por isso, jamais poderá sentir o que sente A. Ainda assim, os cientistas e clínicos que estudam a dor têm desenvolvido uma grande variedade de métodos, dos mais simples até os mais complexos, para documentar quantitativamente os aspectos psicofísicos e emocionais que uma pessoa narra ou exprime sobre a dor que sente (ou sentiu) num determinado momento. Os métodos de análise são utilizados para estudar tanto a dor produzida por doenças como a dor "experimental" gerada por um dano calculado em pessoas voluntárias com fins de pesquisa científica. Esses métodos permitem fazer generalizações sobre a dor e seus mecanismos, assim como avaliar a ação de fármacos analgésicos e outras manipulações terapêuticas que foram desenvolvidas para aliviar a dor.

Nem sempre é possível utilizar seres humanos para pesquisar os mecanismos da dor e a analgesia. Muitas abordagens experimentais invasivas, estudos morfológicos, experimentos farmacológicos etc. devem ser testados em animais de laboratório, geralmente ratos e camundongos. $\mathrm{O}$ experimentador pode aplicar estímulos inócuos ou dolorosos de magnitude calibrada a animal e registrar as respostas em situação de controle, e depois, por exemplo, sob o efeito de um fármaco. O problema está em que esses animais não podem expressar de forma verbalizada ou escrita o que sentem. Afortunadamente, ao longo de toda a escala zoológica existem reflexos musculares que fazem que uma parte do corpo, 


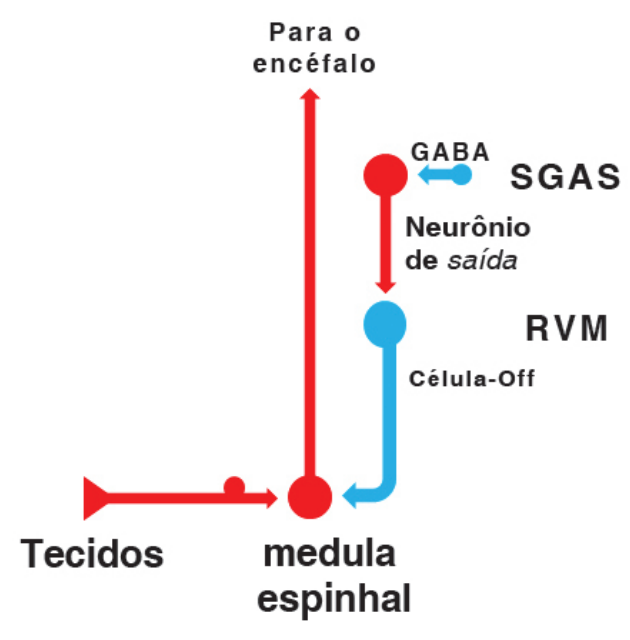

Figura 1 - Esquema das vias ascendente e descendente do sistema nociceptivo. Em vermelho estão os neurônios excitatórios, e em azul, os inibitórios.

GABA - Ácido gama-aminobutírico.

SGAS - Substância cinzenta do aqueduto de Sylvius.

RVM - Região rostroventromedial do bulbo.

por exemplo, uma pata, retire-se rapidamente de um agente que causa dano. A intensidade dos chamados "reflexos de retirada" é um indicador da sensibilidade do animal à dor, tanto em situação de controle como sob o efeito de fármacos analgésicos, condicionamento pavloviano, ou ação de agonistas ou antagonistas sinápticos, e sua medição constitui um recurso valiosíssimo para estudar os mecanismos da dor e da analgesia.

Para que o dano do tecido gere a sensação de dor é necessário que o encéfalo saiba de tal dano (Figura 1). Isso é possível graças ao fato de que as células nervosas que formam os nervos periféricos conectam os tecidos com os neurônios da medula espinhal. Por sua vez, esses neurônios enviam, por um lado, impulsos nervosos que dão lugar aos reflexos de retirada, e, por outro, impulsos ascendentes que atingem várias estruturas do encéfalo até chegar ao córtex cerebral, que é o lugar em que se gera a experiência subjetiva da dor. As descargas de impulsos pelos neurônios medulares constituem dessa forma a mensagem que permite ao córtex cerebral detectar, interpretar e reagir diante do dano tissular. No laboratório, podemos introduzir microeletrodos na medula espinhal de ratos ou camundongos para registrar e quantificar as descargas dos neurônios quando aplicamos estímulos inócuos ou nocivos em alguma parte do corpo e, dessa forma, estudar os mecanismos da dor e a analgesia.

Dentro do conjunto de estruturas nervosas encarregadas da dor existem estruturas no tronco encefálico, tais como a substância cinzenta do aqueduto de Sylvius (SGAS) e a região rostroventromedial (RVM) do bulbo, que são componentes muito importantes do chamado "Sistema Descendente de Controle 


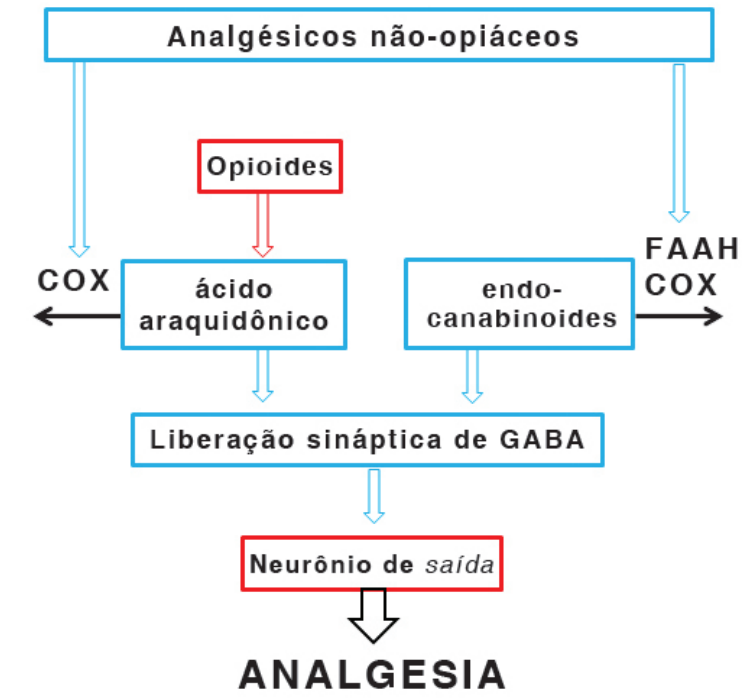

Figura 2 - Diagrama das relações dos opiáceos, os endocanabinoides e os analgésicos não opiáceos com os neurônios da SGAS. Em vermelho aparecem as ações positivas e, em azul, as negativas.

COX - Ciclooxigenases.

FAAH - Hidrolase de ácidos graxos amidados.

GABA - Ácido gama-aminobutírico.

da Nocicepção" (SDCN). Os neurônios da SGAS projetam seus axônios até a RVM, e os neurônios chamados "células-on" e "células-off" da RVM enviam seus axônios à medula espinhal. Aqui, as células-on aumentam e as células-off diminuem a transmissão de impulsos dos neurônios medulares para o cérebro. Dessa maneira, mecanismos tipicamente "cerebrais", como a cognição, a atenção, as emoções, as expectativas etc., podem regular a ascensão de impulsos dolorosos da medula para o cérebro e, portanto, a dor.

O SDCN é também um dos lugares onde agem os opiáceos endógenos (endorfinas e encefalinas) e exógenos (morfina e seus congêneres). Quando os opiáceos, endógenos ou injetados, agem sobre a SGAS ativam-se as células-off da RVM e, assim, inibe-se a transmissão de impulsos dolorosos na medula espinhal e, portanto, a dor. Também descobrimos que os analgésicos não opiáceos (aspirina, dipirona, ketorolac etc.), ao agirem sobre a SGAS, ativam as células-off da RVM e, dessa forma, diminuem a dor. Esse é, portanto, um dos mecanismos de ação tanto dos analgésicos opiáceos como dos não opiáceos. O mais interessante é que o efeito analgésico dos não opiáceos nas SGAS diminui ao bloquearmos com naloxona os receptores neuronais dos opiáceos. Como os analgésicos não opiáceos não agem sobre os receptores de opiáceos, o efeito da naloxona demonstra que os analgésicos não opiáceos estão agindo na SGAS por meio dos opiáceos endógenos. 


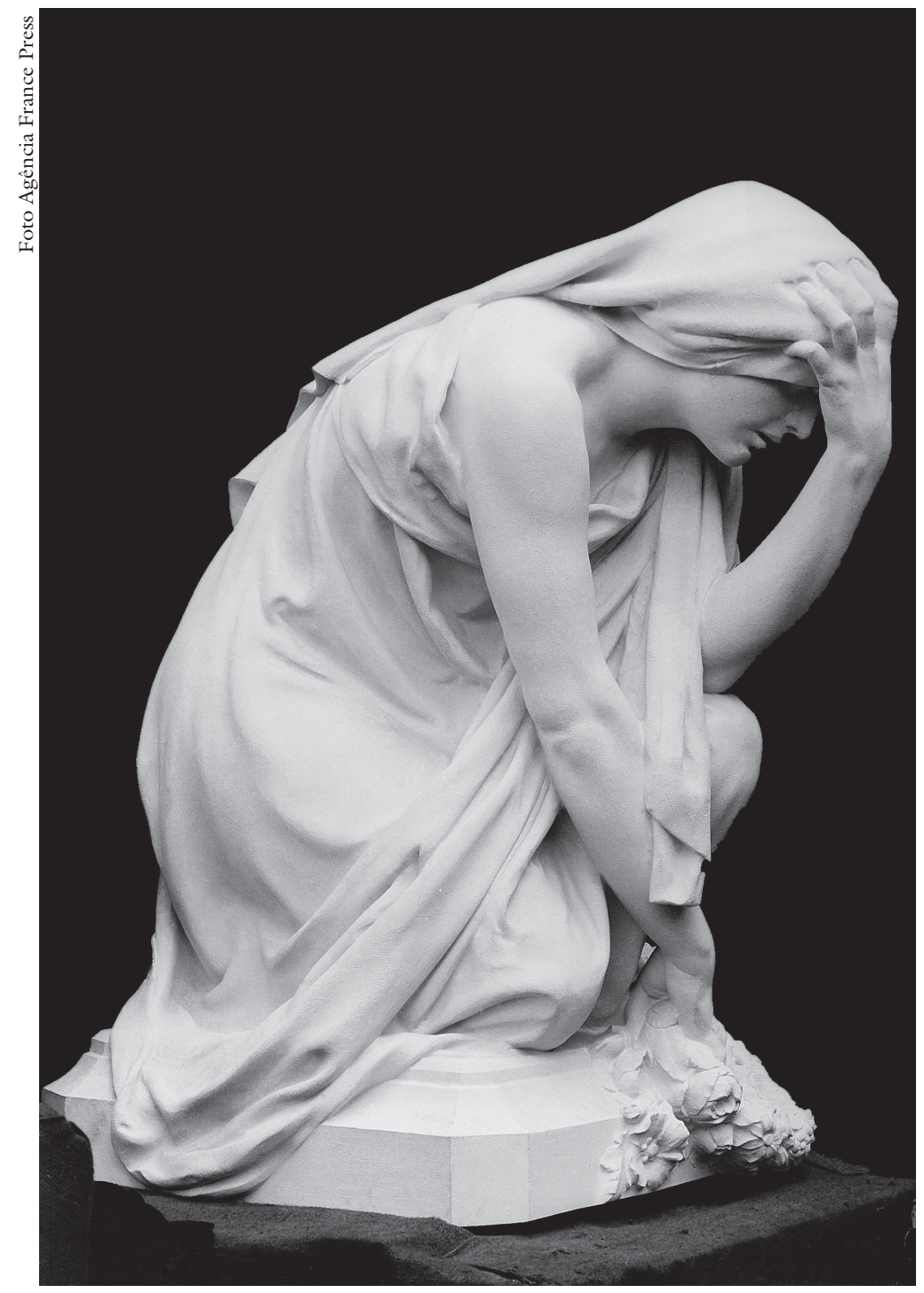

Emmanuel Dolivet, La Douleur, 1911.

Essa conclusão está apoiada no seguinte experimento. Tem sido demonstrado amplamente que a microinjeção repetitiva de morfina ou outros agonistas do tipo $\mu$ na SGAS induz analgesia no começo, mas tal analgesia vai diminuindo com as microinjeções sucessivas; é o que se chama de "tolerância". Descobrimos que a microinjeção na SGAS de dipirona ou aspirina também induz tolerância a esses não opiáceos e, eis o interessante, simultaneamente induz tolerância cruzada à morfina. É como se no lugar dos não opiáceos tivessem sido administradas injeções repetitivas de morfina.

Além dos opiáceos endógenos, nosso corpo produz outros analgésicos, os quais, por agirem de maneira semelhante aos componentes da maconha (Cannabis sativa), chamam-se endocanabinoides. Os canabinoides, tanto os endógenos quanto os exógenos, induzem analgesia quando agem sobre seu receptor CBI na SGAS. Recentemente demonstramos que, como acontece com os re- 
ceptores de opiáceos, se bloquearmos os receptores $\mathrm{CBI}$ diminuiremos o efeito analgésico da dipirona na SGAS, o que indica que também os endocanabinoides contribuem com o efeito analgésico dos não opiáceos.

Como se poderia explicar, então, a interação dos analgésicos não opiáceos com os opiáceos endógenos e com os endocanabinoides na SGAS? Muitas descobertas prévias apresentam a existência dos seguintes mecanismos (Figura 2): na SGAS há neurônios de saída cujos impulsos fazem que se ativem as células-off da RVM e, dessa forma, induza-se a analgesia. Os neurônios de saída da SGAS estão continuamente inibidos por neurônios GABAérgicos locais, o que garante certa sensibilidade à dor. Se a inibição GABAérgica diminui na SGAS, aumenta a atividade dos neurônios de saída e se produz analgesia. Os opiáceos endógenos ou exógenos, ao ativarem os receptores $\mu$, aumentam a concentração de Ácido Araquidônico (AA) nos neurônios GABAérgicos; o AA é, por sua vez, transformado pela 12-lipoxigenase em compostos que diminuem a liberação de GABA, aumentando assim a atividade dos neurônios de saída. Por sua vez, os analgésicos não opiáceos inibem as ciclooxigenases (COX) que normalmente transformam o AA em prostaglandinas e tromboxanos. Ao inibir os COX poupa-se AA, que é processado pela 12-lipoxigenase com a subsequente diminuição da liberação de GABA. O AA é, portanto, o elemento no qual os analgésicos opiáceos e não opiáceos convergem na SGAS para induzir analgesia.

Por sua vez, os endocanabinoides normalmente inibem a liberação de GABA, mas são constantemente metabolizados pela hidrolase de ácidos graxos amidados (FAAH) e pelas COX. Os analgésicos não opiáceos inibem não só as COX, como também a FAAH. Quando esses analgésicos são administrados, poupam-se, portanto, endocanabinoides, e isso diminui ainda mais a liberação de GABA. A FAAH e as COX representam então o ponto onde convergem os endocanabinoides e os analgésicos não opiáceos na SGAS para induzir analgesia.

Obviamente, a ação dos opiáceos, dos canabinoides e dos analgésicos não opiáceos na SGAS faz que, finalmente, os neurônios de saída sejam liberados da inibição GABAérgica e essas disparam então a inibição descendente que diminui a transmissão de impulsos dolorosos na medula espinhal e, dessa forma, diminui a dor. Além disso, é uma grande vantagem o fato de que os analgésicos de venda livre possam aproveitar, pela sua ação, os mecanismos endógenos que todos nós possuímos.

Horacio Vanegas F. é Ph.D pela Yale University (Estados Undidos). Pesquisador no Instituto Venezolano de Pesquisas Científicas (IVIC). @ - horaciovan@gmail.com

Tradução de Diego Molina e revisão do Prof. Dr. Luiz Roberto Giorgetti de Britto. O original em espanhol - "La aspirina, los opioides y la marijuana en el sistema endógeno de control del dolor" - encontra-se à disposição do leitor no Instituto de Estudos Avançados da USP para eventual consulta.

Recebido em 10.12.2012 e aceito em 21.12.2012. 